\title{
SCHÄFER ON THE TEMPORAL AND OCCIPITAL LOBES.
}

BY DAVID FERRIER, M.D., F.R.S.

THE opponents of cerebral localisation-a race well-nigh extinct-make capital out of the fact, that the advocates of this doctrine are not agreed among themselves as to the exact extent of the areas or regions supposed to be endowed with specific functions. They will therefore welcome with satisfaction the contribution to the physiology of the cerebral hemispheres, by Professor Schäfer, in the last issue of this Journal. ${ }^{1}$

In this paper, Professor Schäfer not only differs in important respects from all who have preceded him in this. field of enquiry, but exhibits the curious spectacle of one who believes in the rigid localisation of a visual sphere, a centre for common or tactile sensibility, and differentiated motor centres, and yet contends that the important senses of hearing, taste, and smell have, apparently, no local habitation in the brain. For he can obtain no evidence of impairment even, not to mention abolition, of any of these faculties on destruction of any portion of the cortex. And in particular, he asserts, that the temporal lobe-in which it is now very commonly believed that these faculties are centralised, and where alone it would seem they can be, if not diffused among regions already otherwise occupied-may be completely removed on one or both sides, leaving hearing, taste, and smell absolutely intact.

While he thus abounds in negations, Professor Schäfer, who has done some good work in cerebral localisation, gives us no clue to the situation of the centres whose supposed seat he so

1 "Experiments on Special Sense Localisations in the Cortex Cerebri of the Monkey."-'Brain,' Jan. 1888. 
ruthlessly demolishes; and he is unable to indicate any use of the temporal lobe, except that its removal on both sides is in some way the cause of a temporary idiocy.

To one who has accepted the principle of localisation in respect to vision, tactile sensibility, and special motor faculties, this should appear a most lame and impotent conclusion.

It is difficult to believe, that Professor Schäfer can have formulated to himself the logical consequences of the position. he has taken up, without having had serious mistrust raised in his own mind as to the completeness of his lesions, or the reliability of his methods and observations. But if he has, his faith in his methods must be of an extremely robust character, if it can have impelled him to assume such an equivocal position, and oppose himself to the combined evidence of comparative anatomy, clinical pathology, and actual experimental demonstration.

As I have, in my work on 'The Functions of the Brain,' (page 310) attributed to Professor Schäfer (and his former colleague, Professor Horsley) opinions respecting the auditory centre altogether at variance with those which he now maintains, it is necessary that I should, in the first place, endeavour to clear myself of the charge of having misrepresented him.'

In a letter dated March 19th, 1885, Professor Schäfer wrote to me as follows: "We have some monkeys just now which you ought to see. The whole of the temporo-sphenoidal lobe, including the hippocampus, has been remored in them, and we cannot detect any paresis of sensation (except anditory)."

I did not. however, doubt the accuracy of my own observations, and, at my request, Professor Schäfer and his colleague consented to perform the experiment under my supervision and direction. When this was carried out, I had no difficulty in demonstrating to their satisfaction that the lesion had caused profound impairment of common and tactile sensibility on the opposite side of the body. And I had the further pleasure of suggesting to them, and seeing performed, experiments which I had myself planned, viz. the extension of the lesions into

\footnotetext{
' A charge which I observe is made in the 'Phil. Trans.' 1888, B. 20, p. 20,
} footnote. 
the gyrus fornicatus, or anterior division of the limbic lobe. The results of these experiments demonstrated the physiological unity of the callosal and hippocampal gyri, and confirmed the unity which Broca had indicated on anatomical grounds.

I naturally gathered from Professor Schäfer's letter that he had obtained evidence of the existence of an auditory centre in the temporal lobe. For he expressly excepted auditory from the negative effects as regards other forms of sensibility.

And as he had informed me that-in harmony with my own experiments-he had obtained no indications of impairment of hearing on destruction of the rest of the temporal lobe, apart from the superior convolution, I considered myself justified in quoting his. results as confirmatory of my own. Professor. Schäfer is of course entitled-nay bound-to change his views, when the evidence on which he based them appears on further consideration to be insufficient; but $I$ do not think that I can be said to have seriously misrepresented them as they at that time stood.

Professors Schäfer and Horsley had given me an opportunity of testing, and I am happy to say of correcting, conclusions which they were inclined to draw adverse to my own. But the first intimation I had of Professor Schäfer's further investigations (in conjunction with Dr. Brown) was the announcement at a meeting of the Physiological Society on February 12th, 1887, of the views which he had already then arrived at, and now puts forward in a more elaborate form. These were first published in the 'Proceedings of the Physiological Society,' No. 2, 1887. I criticised them at the time, and at a subsequent meeting of the Neurological Society, I strongly deprecated this premature publication of conclusions while the evidence was incomplete-seeing that the animals were still alive, and the actual lesions undetermined-as being likely to do harm and prejudice dispassionate enquiry. And I particularly called attention to-and here emphasise-the difficulties that have to be encountered, and the fallacies that are apt to be committed, in investigating the sense of hearing in the lower animals. Care must be taken to discriminate between the sense of hearing proper, and mere reflex reaction to sudden, 
sharp, or lond sounds, a reaction not incompatible with real deafness. Mere coincidences in animals keenly on the alert to everything going on around them, must be scrupulously eliminated. The tests of hearing should be such as to entirely avoid attracting the animal's attention by other channels of perception, such as sight, imitation of other animals, a sense of proximity conditioned by vibration, agitation of the air, and such like. The animal's present behaviour should be compared with its past, or with that of normal monkeys under conditions of variation in sound, and special kinds of sound, only, all other things remaining the same. And even then, it often requires long and laborious investigation to eliminate all sources of fallacy. Professor Schäfer is evidently satisfied that he has avoided all sources of fallacy himself, and he quotes in support of his conclusions the opinions of a Committee of the Neurological Society in favour of the retention of hearing in two of his experimental animals, in one of which he says he had scooped out the superior temporal convolution on both sides, "so that not a trace of the convolution in question should remain" (Fig. 5); and in the other he had removed not only the superior temporal convolution, but even the whole temporal lobe on both sides (p. 373). ${ }^{1}$

But Professor Schäfer's figures (Figs. 5 and 6) of the brains of these monkeys must be regarded more as a sort of pictorial representation of his own idea, or wish, as to the extent of the lesions, rather than of the reality. Having myself examined both preparations, I most emphatically deny the accuracy of Professor Schäfer's diagrams. In neither the one nor the other were the superior temporal gyri completely destroyed :-considerable portions remaining absolutely intact in both hemispheres, and notably so in the brain which Fig. 6 professes to

1 Profezsor Schäfer has committed a slight irregularity in quoting the opinions of a Committee, before the members of the said Committee had met together, or formulated any report of their proceedings.

In the absence of any information as to methods aud tests employed by the visitors appointed by the Society. I am willing, without criticism, to attach the utmost weight to the opinions at which they arrived. But of this I have no doubt whatever, that if the evidence of hearing in the animals submitted to their investigation was indubitable, the explanation is to be found in the fact, that the superior temporal gyri were not completely removed in any one of thom. 
represent. And considering how extensive lesions may be in any given centre-witness the visual centre-without total annihilation of its functions, nothing short of absolute destruction, primarily or secondari]y, is likely to abolish all vestiges of the sense to which it is related.

But apart from Professor Schäfer's experiments, let us proceed to consider the question of the locality of the sense of hearing on broader grounds. The evidences of the localisation of the centre of hearing in the temporal lobe-mand according to my view, in the superior convolution of this lobe -are as follows: First, the reaction on excitation by the electrical stimulus-a reaction which afforded me the suggestive indication, leading to the verification by destructive lesions, of the relation between this convolution and the faculty of hearing. Electrical irritation of the upper two-thirds of the superior temporal convolution causes a quick retraction \&. pricking of the opposite ear, as if towards the supposed orig若 of the sound, combined generally with turning of the heat and eyes to that side, and dilatation of the pupils. I have used the term "pricking" as synonymous with retraction and pointing of the auricle in the direction to which sound woul naturally be referred. I have nowhere described the reaction as a " pricking forward of the ear," such as Professor Schäfềr attributes to me (p. 373). The reaction is precisely that which an animal makes when a shrill sound is made towards one side, as may be easily verified in any monkey, or such animal as the cat, whose ears, when at rest, are pointed and directed forward. In the lop-eared rabbit, however, irritation of the homologous region causes sudden elevation of the eat, as well as retraction and exposure of the mouth of the auricte towards the referred origin of the sound. Professor Schäf苑 says that excitation of very various parts of the cortex (fronta region, middle temporal gyrus, angular gyrus, and occipita lobe) produces "almost precisely the same effects" (p. 372). As I was myself the first to point out the various positions from which movements of the head and eyes to the opposite side might be stimulated, it is scarcely likely that I should describe the movements of the head and eyes as a reaction peculiar to the superior temporal convolution. The special 
feature of this reaction is the sudden retraction of the ear which occurs on irritation here, and here only. Professor Schäfer's ingenuousness is not very apparent when he endeavours to conceal the significant differences between the reaction of the superior temporal convolution and that of the other regions above enumerated, under the words "almost precisely the same effects."

Next, as regards the evidence from destructive lesions, as supplied by my own experiments, and those which I made in conjunction with Professor Yeo. This consists of an extensive series of experiments reported in detail in the 'Philosophical Transactions,' Part 2, 1875, and Part 2, 1884, involving divers lesions of the temporal lobes;-negative as regards affections of hearing when the superior temporal convolution was intact, and positive when this was destroyed unilaterally and bilaterally; and all mutually corroborative of each other. No greater importance is attached to these experiments individually, than as links in a chain leading up to the conclusive demonstration which was given before the Physiological section of the International Medical Congress in 1881.

In one of the series in which the superior temporal convolution was destroyed on both sides in the upper two-thirds of its extent (the left angular gyrus having been destroyed previously but without permanent effects), the following notes were made as to the condition of the animal on the day after the operation. ${ }^{1}$

“April 8th, 10 A.M.-Animal alive and active, and jumped out of its cage when the door was open. Sight was good, and tactile sensation unimpaired. Various experiments were made to ascertain the existence or not of hearing; but it was difficult to devise a test, as the animal was continually on the alert; and it was not easy to make a sound withont in any way attracting its attention by sight. The following method was tried: While the animal was sitting quietly by the fire, I retired to the other room, and while watching through the chink of the half-shut door, called loudly, whistled, knocked on the door, tinkled glass, \&o., without ever cansing it to look round, or give any aign of having heard. I then cautiously approached the animal, and not till it saw me did

1. Seo Experiment 15, ' Phil. Trans.,' vol. 165, part 2, 1875. 
it give any sign of conscionsness of my presence. When the same experiment was repeated, while the monkey and its companion were quietly seated by the fire enjoying the heat, it gave no sign of hearing; while its companion started with alarm, and came with curiosity to ascertain the cause of the sound. . . 8 8 P.M.-In the presence of Dr. Burdon Sanderson I repeated the various tests with the view of eliciting signs of hearing. To all it remained without response. It seemed unconscious of my presence when speaking close to its ear, and only started when it caught sight of me."

The last of the series confirming the presence of, and establishing the permanency of, similar symptoms was the now somewhat famous monkey exhibited at the International Medical Congress. In view of certain questions that have been raised as to the exact condition of this animal, I give here verbatim the rough notes written down from day to day.

The subject of the experiment was an unusually active and intelligent monkey, in full possession of all its faculties.

It was designated Monkey F. The extent of the lesions, superficial and deep, in this animal are faithfully represented by photography on Plate 22, Figures 23-38.1

"June 23rd (24 hours after the operation).-F. to-day is rather dull and drowsy-looking. Some codema of face and ejelids. Right eye partially closed, the left open. Put out its hand and touched companion sitting near it and eating a piece of bread. It gives distinct signs of perception of touch on hands, feet, ears; moves about perfectly freely. Pays no attention whatever to the loudest sounds which startle the other monkeys, or to whistling, tapping, \&c., close to its ears. Oil of bergamot placed on a rod and held at its nostrils cansed it to sniff apparently and make movements with its lips. Acetic acid canses it to retract its head sharply, and sneeze or snuff ont. Acetic acid to lips causes licking movements of tongue; so also common salt placed on lips. Sees perfectly well, and goes about from one cage to the other through small doór.

"June 25th.-F. is very bright and active; rans about actively climbs up bars of cage, and peers eagerly through bars at what is going on. Takes things offered it. Took a piece of date, smelt it and threw it down; so also a piece of bread. Took next a piece of cold builed potato, smelt it, rubbed it in its hands, and began to

voL. XI.

$$
1 \text { 'Phil. Trans.;' p. 2, } 1884 .
$$




\section{SCHÄFER ON THE TEMPORAL AND OCCIPITAL LOBES.}

eat with relish. Pays no attention to sounds-tapping, scratching, \&c.- On side of cage, which alarm its companion toward either side. This was carried on repeatedly for the space of an hour without eliciting any sign of perception. Going down to the place where the animals are kept, sets all the others on the qui vive. No sign of this on the part of F. But as soon as I come within sight, it looks interested and comes to the bars and looks up.

“June 27th.-Examined F, with Dr. Lauder Brunton. Tried various tests, sounds, whistling, \&c. Could not decide positively. Animal occasionally turned its head, but whether coincidence or hearing, doubtful. At any rate, conclusion arrived at that if the animal not absolutely deaf, its hearing was profoundly affected. Noted that the ears did not twitch as in the case of the companion monkey; nor did it show alarm at sounds.

" June 28th._F. placed in a separate compartment. Did not reply to plaintive cries of its companion. F. tried constantly to see its cumpanion through small apertures in cage. Loud sounds, which made all the others start and look frightened, caused generally not the slightest eign on the part of $F$. Occasionally it tarned its head coincidently with the noise, but whether hearing, very problematical, as at other times no such sign. The ears did not twitch; nor any nervous wincing as in the case of the companion. No response to cries or calling by name. Sight, motor power, and tactile sensibility perfect to all tests.

"June 30th.-Repeated the tests with the same result as formerly. The animal is mostly totally unconcerned when its companion is in ebject terror, shrinking, winking, and twitching its ears. Every now and then, doubt seems raised by the animal looking at the same time as a noise is made.

“ July 2nd.-Again examined the animal carefully with Dr. Yeo. In response to various tests-sounds of various kinds-there was most commonly no indication of perception, such as the companion monkey showed by shrinking, grimaces of terror, cries, and twitching of the ears. Occasionally the animal would turn its head coincidently with the sound. But this is only if a sound made towards stairs leading down to cage, where it in general directed its attention spontaneously. Conclusion : if not absolutely deaf, hearing very doubtful, and at least no impairment of the other powers of the animal.

"July 5th.-Made several experiments with electric bell placed against side of cage. On ringing it, the companion was at first very anxions about the sound, while $F$. paid no attention, but after a time it ceased to regard it. Cannot yet be sure whether the animal hears at all, but certainly is not at all disturbed by 
sounds which make the others start, twitch ears, wink, \&c. No twitching of the ear in F. Otherwise perfectly well. Runs about; is very expert in catching flies, which it watches carefully and pursnes skilfully. Very much on the alert to all that goes on, and occasionally utters a grunt if it sees anything like water, food, \&c., which it wants. Never, however, replies by grunts to those of its companions, and is generally perfectly silent. Formerly it was continually in the habit of grunting, \&c., in reply to name, \&c.

"July 7th.-Have been making numerons experiments, also Dr. Yeo, as to whether the animal hears the noise of a percussioncap exploded near. It is most difficult to judge. Occasionally it seems to start coincidently with the sound, and yet at other times gives not the slightest sign, while the others invariably start. The dressings removed to-day; all aseptic ; wound perfectly healed. Animal well and vigorous, very much on the alert. The ears are now mobile. It moves them during its actions of attention, but I have not jet been able to ascertain definitely whether they twitch to sound. This afternoon, at six, made an interesting experiment while sitting in the cage with its companion (G.), and both quite still, and engaged in examining each other. I made repeatedly a scraping sound on floor with foot as if going up to cage. The companion G. invariably opened its eyes and looked up, whereas there was never any sign on the part of $F$.

"Suly 13th.-Examination to-day confirms former remarks. Once very clearly percussion-cap excited G., and met with no sign of response from F. Does not answer calls like $G$., and pays no attention to sounds which cause G. to look up.

"July 15th.-Well and active. Gives no signs of recognition to cries, and frequently not the slightest sign of movement, or attention to shots. It is more than donbtful whether there is any reaction at all.

"July 20th.-Condition unchanged.

"July 27th.-Owing to the death of G., F., which has been disconsolate, and occasionally uttering plaintive cries, was transferred yesterday to the cage of $C$. (hemiplegic). The two seemed to agree tolerably well, with the exception of squabbles as to food-C. being very indignant, and occasionally attacking F. for seizing the food first. Made various experiments as to hearing, and it seems that the signs of reaction (which have caused so much doubt) to sounds are less evident. The electric bell was transforred to the side of its cage Ringing it suddenly, caused C. to the very much disturbed and annoyed, whereas $F$. paid no attention whatever. Coming duwnstairs to the place where the animals are kept, I observed C. looking out attentively, but $F$. 


\section{SCHÄFER ON THE TEMPORAL AND OCCIPITAL LOBES.}

remained in back of cage, not coming forward until such signs on the part of C. as to attract notice. Repeated percussion-cap experiments several times $C$. invariably started, but to-day I failed to detect any unequivocal indication of this on the part of F. $\mathrm{As}^{-}$to other sounds-calling, whistling, \&c.-F. pays no attention whatever, whereas the attention of the other monkeys is at once excited. The animal is excessively on the alert, and it follows every movement, and is with difficulty surprised.

“ July 29th.-The percussion-cap experiment, repeated to-day several times in the presence of Dr. Yeo and J. G. Romenes, was every time negative, causing no reaction or starting, while its companion was invariably much startled and annoyed.

"August 4th.-The animal was exhibited to-day before the Physiological section of the International Medical Congress. A percussion-cap was exploded close to it several times before the andience, and it gave no sign whatever of starting; whereas $C$. started very emphatically.

"December 12th.-The animal has kept in excellent health, and is most lively, and continually engaged in active gymnastics. Many experiments were made with the viow of testing its hearing. Sometimes it appears to start when a pistol-cap is exploded, so that occasionally it is judged to hear. To-day tried the experiment of calling from the top of stairs. The other monkeys [2] are both on the alert, looking eagerly and making sounds of expectation; but F. pays no attention whatever, and goes on with its own occupation quite unheeding. It does not pay any attention to scratching on cage as the others do, and in general does not respond to sound-calls, \&c., which always excite the attention of the others. It does not utter sounds in reply to calls. Occasionally, when left all alone, it utters a short cry of loneliness.

"March 31st.-While sitting to-day having its back scratched, a pistul-cap was exploded close to cage; not the slightest start, though the others and Mr. N., who was scratching the monkey, made a sudden start.

"July 27th.-The animal has remained well and lively without showing any new symptom, and still to all appearance exactly in the same condition as before as regards hearing. To-day, made another series of observations of the animal while in its cage, and also after it was removed and placed in a small cage on table. Loud whistling, knocking, ringing electric bells in the neighbourhood failed to elicit any sign of attention. Occasionally, as before, there was an appearance of a start, or a look round, apparently conditioned by the noise, but repeated experimentation showed that this was pure coincidence." 
I was not a little amused at listening to Professor Schäfer's comments on the above record which I read before the Neurological Society. First, he suggested that the notes themselves showed that the animal was not really deaf. And this, I admit, was in some respects an intelligible and fairly defensible position to assume. For doubts were constantly being raised, as the record freely states, in $\mathrm{mv}$ own mind as well as in that of other observers.

It was only after long and repeated investigation, and variation of tests, that our doubts as to the animal's true deafness seemed fairly dispelled.

The only reaction which might be interpreted as a sign of some obscure sense of hearing was the occasional start coincidently with a loud or shrill sound made in its neighbourhood. But even granting that this was not mere coincidence, it might be due to some remnant of the centre, or co-exist with abolition of true auditory perception, and resemble the reaction to loud sounds which may be elicited in animals entirely deprived of their cerebral hemispheres, as Flourens and Longet demonstrated long ago.

But almost in the same breath Professor-Schäfer next suggested that we had in truth lighted on a specimen of a monkey stone-deaf before the operation. It has been said that a dead donkey is difficult to find. A deaf monkey will be a greater curiosity. And when Professor Schäfer succeeds in finding one, it will not help him in his argument, as this animal's hearing powers were, as the record shows, well. established before it was submitted to operation.

Professor Schäfer does not in his paper expressly repeat his brilliant inspiration, but, with a generosity which I do not fail to appreciate, he sums up his estimate of the evidence which Professor Yeo and I have given as to the localisation of the auditory centre, with the declaration of his belief, that he is " justified in asserting that the supposed localisation of the auditory perceptive faculties in the temporal lobe in monkeys, has no experimental evidence in its, favour" (p. 377). Without disputing the accuracy of the views of Munk and Luciani, who have satisfied themselves that lesions of the temporal lobes in dogs cause total abolition, or profound 
impairment, of the. sense of hearing, he apparently takes comfort from the fact, that these physiologists have not actually experimented on monkeys. I am not concerned to speak for Munk or Luciani-believing, as I do, that they are both wrong as to the exact definition of the auditory centre in the temporal lobe-but they themselves, and doubtless all who believe in comparative anatomy and physiology, have no hesitation in extending their conclusions to monkeys and man. For if the localisation of an anditory centre is true of dogs, it must $\grave{a}$ fortiori be true of higher animals, in which cerebral localisation is more conspicuously manifest.

If, however, it should still appear that the results of experiments on the lower animals are not absolutely conclusive, let us turn to the records of human pathology, which is, after all, the ultima ratio in questions relating to subjective conditions, not clearly indicated by external manifestations. Deafiness from cerebral disease is undoubtedly a rare occurrence. That this should ensue, requires the existence-rarely happening —of symmetrical lesions in both hemispheres; for unilateral lesions of the auditory centre do not appear to cause, at least permanent, affections of hearing. But as destruction of the motor centres of articulation in the left hemisphere causes aphasia, so destruction of the auditory centre on the left side causes the now universally recognised condition known as "word-deafness," a condition alone explicable on the hypc thesis of the existence of an auditory centre. In every instance of this kind which has been examined post-mortem, the destructive lesions have involved the temporal lobe, and in all, the superior temporal convolution.

I have been able to find only two uncomplicated cases of symmetrical lesion of this region in both hemispheres, but both are of transcendent importance. Shaw ${ }^{1}$ has recorded the case of a woman, ætat. 34, who, two months before her admission into his asylum, lost power in the right arm, and soon after had a sudden apoplectic seizure resulting in loss of speech and deafness. The loss of power in the right hand soon passed off. She became incoherent, more or less

1 'Archives of Medicine,' Feb. 1882.-Absțract in 'BraIN,' Vol. V., 1882-83, p. 430 . 
maniacal, and demented. On admission, she was found to be perfectly deaf and blind. She died of pneumonia a year afterwards.

Post-mortem examination showed complete atrophy of the angular gyriand superior temporo-sphenoidal convolutions of both hemispheres (see figures accompanying the paper). The grey matter of the atrophied regions had entirely disappeared, leaving the outer layer attached to the pia mater, with a cavity underneath formed at the expense of the grey matter.

The cranial nerves were normal in appearance, the optic nerves showed increase of the connective tissue septa, atrophy of the nerve-fibres, and spaces filled with a colloid-like material.

This case may be objected to, as not being absolutely conclusive, owing to the fact, that possible disease of the organs of hearing is not expressly disproved in the record; though the sudden onset of deafness coincidently with the cerebral seizure would almost of itself negative such a hypothesis.

No such objection can be urged against the following case reported by Wernicke and Friedländer. ${ }^{1}$ As this case is so important, I give the following particulars at some length.

A woman, aged 43 , who had never suffered from deafness or affection cf vision, was attacked on the 22nd of June, 1880, with right hemiplegia and aphasia. She remained in the hospital until August 4th, when she was discharged. At this time the patient could speak, but she spoke unintelligibly, and was sometimes believed to be intoxicated. She not only could not make herself understood, but she could not understand what was said to her. She was received into the hospital again on September 10th, with slight paresis of the left arm. The right hemiplegia had entirely disappeared. The patient was looked upon as insane. She was absolutely deaf, so that she could not be communicated with. She died of an attack of hæmatemesis on the 21st of October. An extensive lesion was found in each temporal lobe, invading the superior temporal convolution on both sides (see figures

1 'Fortschritte der Medicin,' "Ein Fall von Taublseit in Folge von doppelseitiger Lacsion des Schlïfelnppens," Band i., No. 6, March 15th, 1883. 
accompanying paper). The rest of the brain exhibited no abnormality; nor were there any conditions leading to increase of the intra-cranial pressure and possible affection of the cranial nerves. It was proved that the patient had previously enjoyed excellent hearing. Her total deafness occurred rapidly in connection with the other indications of cerebral disease. In order to exclude possible local affection of the ears, these organs were submitted to examination by Professor Lucas. The result of this examination was practically entirely negative, only a slight dry catarrh being found, and nothing locally to account for deafness.

This case will, I venture to believe, be held to justify the conclusions drawn by the authors themselves, viz. "that the auditory nerves ultimately end in the temporal lobes, and that double or bilateral lesion in these lobes causes complete deafness. It may therefore be stated with all certainty that the temporal lobes are the cerebral centres of hearing."

And I should myself go further and say, that the case is entirely in harmony with my own more strict localisation of the auditory centre in the superior convolution of this lobe.

The experimental evidence in favour of the localisation of special centres of smell and taste, which has, up to the present, been adduced by myself in the case of monkeys, and by Munk and Luciani in dogs, cannot be said to possess such precision in respect to the position and extent of these centres as not to stand in need of further investigation. My own work in this direction has been mainly that of the pioneer. But these experiments, with all their deficiencies and imperfections, taken by themselves alone, furnish at least a strong presumption, that the olfactory centre is situated in the hippocampal region of the temporal lobe, at its lower extremity. But when taken with the comparative development of the hippocampal or pyriform lobule in osmatics and anosmatics, and the anatomical relations of this region to the olfactory tract, and anterior commissure, they constitute a body of evidence in favour of the localisation of the olfactory centre mainly, if not exclusively in this situation, which I venture to think will not be considered as materially weakened by Professor Schäfer's inability to detect any impairment of the sense of smell in 
those animals in which he professes to have completely removed this lobe.

Investigations as to the sense of smell in the lower animals are perhaps more difficult than that of any of the other sensory faculties, seeing that the external manifestations of olfactory perception proper-apart from those caused by substances possessing some degree of pungency and not strictly pure olfactory stimuli-are not so evident as to ensure detection without a long previous study and minute acquaintance with the habits of the animal.

But inasmuch as Professor Schäfer, while unable to confirm, is also unable to adduce any facts opposed to the positive results obtained by Munk, Luciani and myself, it does not seem necessary to discuss the question at greater length. I would only remark that, if Professor Schäfer is right in his conclusions that the whole of the temporal lobe, including the cornu Ammonis and bippocampal lobule, may be removed without abolishing or impairing the sense of smell, he must be considered as having proved more than he could wish :viz. that comparative anatomy is a delusion and a snare.

The exact position of the gustatory centre is admittedly less clearly defined than any other.

I have related two experiments ${ }^{1}$ in which the lower half of both temporal lobes was extensively disorganised. In these animals no reaction was induced by placing on the tongue such substances as aloes, citric or acetic acid, which in normal monkeys excite active expressions of disgust and discomfort. I do not profess to have determined the connection between these symptoms and the destruction of any particular region more precisely than that above described; nor were the animals kept sufficiently long alive to decide the question as to their permanency, but the observations are not without important significance.

Professor Schäfer objects, that the animals "were in an entirely abnormal condition when tested, nor was the testing performed with purely sapid substances, but with acid and aromatic particles." ${ }^{2}$ The only abnormal conditions present

1 Fxperiments 14-15, ' Phil. Traus.,' vol. 165, Part 2

2 P. 378, focotnote. 
in these animals, different from others similarly tested, were the position of the lesions:- -viz. in the lower half of the temporal lobes. And even if aloes, colocynth, citric and acetic acids are not "purely sapid substances," but "also acid and aromatic particles," the objection to their use seems somewhat irrelevant, seeing that no reaction whatever was induced by any of them.

Let us now turn to Professor Schäfer's urterances in respent to the visual centre of the cortex. The chief point at issue between him and myself is the anterior boundary of the visual zone. While he considers it as being sharply bounded by the parieto-occipital fissure, I maintain that it embraces also the angular gyrus-the two constituting together what $I$ have termed the occipito-angular region.

With respect to the effects of electrical irritation of this region, it is true that while invariably obtaining movements of the eyes from the anterior and posterior limb of the angular gyrus-and in this I am absolutely confirmed in every instance by Luciani and Tamburini-I did not observe similar movements, or other external manifestations, on irritation of the occipital lobes alone. But inasmuch as Luciani and Tamburini did occasionally observe similar movements of the eyes on irritation of the occipital lobe, though less marked than in the case of the angular gyrus, and as Professor Schäfer seems to have had no difficulty in always obtaining the same, I am not disposed to question the accuracy of their results, and will admit that I may have overlooked them, though actually present in the ten animals on which $I$ experimented ; or that the parts may have lost their usual excitability owing to some temporary conditions. But this admission only strengthens the position which I have maintained. For if the same, or similar, movements are capable of being excited from the occipital lobe, as well as from the angular gyrus, the presumption is that the regions in question have a community of function. And I am glad to observe that Professor SchäfeI adopts my view, that these movements are the expression of subjective visual sensation. ${ }^{1}$

Professor Schäfer is unable to confirm the results obtained

1 Procedings of the Roy. Soc., March 1, 1888. 
by myself (and in conjunction with Professor Yeo) on destruction of the angular gyrus; and he is inclined to attribute such effects as we have observed to mere functional perturbation of the true visual centre situated in the occipital lobe.

I will, for the purposes of argument-but only so faradmit that the temporary total blindness consequent on bilateral destruction of the angular gyrus, may be explained in the manner suggested by Professor Schäfer; and I will therefore exclude these experiments from consideration. But inasmuch as it is held by Professor Schäfer, Munk, and others, that unilateral destruction of the visual centre always causes homonymous hemiopia, and not crossed blindness, or amblyopia, the results of destruction of the angular gyrus, if merely attributable to functional perturbation of the occipital lobe, should in all cases assume the form of hemiopia. How then are the following facts to be explained in accordance with this hypothesis?

In one animal ${ }^{1}$ the left angular gyrus was cauterized with the galvanic cautery.

"The left eye was secured, and the animal allowed to recover from stupor. At the end of half an hour, it was evidently wide awake, but would not move unless touched. At this time it was removed from its cage and placed on the floor, whereupon it began to grope about in a sprawling manner, knocking its head against every obstacle. After some minutes of this behaviour, it subsided, and refused to move. It made no sign of fear at threatening gestures, and did not wink at a thrust of the finger at its eye, until the finger almost touched the conjunctiva, when the usual reflex closure occurred. Half an hour later, the same tests were employed with precisely the same indications of total loss of vision. At the end of still another half an hour, while it was lying quietly in its cage, it was gently laid hold of without noise to attract its attention, whereupon it bounded away with an expression of fear and surprise, and ran full tilt against the leg of the table, where it remained groping and sprawling for a few minutes. It then started off, and this time ran against the wall, against which it sprawled helplessly. Similar things are repeated. It gave no sign of perception when it was cautiously approached without noise. But when a slight noise was made with

1 Experiment 5, 'Phil. 'Trmus., Part 2, 1884. 


\section{SCHÄFER ON THE TEMPORAL AND OCCIPITAL LOBES.}

the lips quite close to it, it darted off and came against the wall as before, where it lay down. Half an hour later, while it was resting quietly in a corner, with its eye open, the light of a lantern was flashed in its eye, but it gave no sign. Creoping up to it cantionsly without exciting its attention, the observer made a slight whisper close to its face, whereupon it peered eagerly; but evidently remembering the results of running away, it crouched down and would not move. Half an hour later, when it was quiet in its cage, it started suddenly on being touched, and ran its head into a corner, where it crouched.

"Next day, its left eye being still closed, it showed unmistakably the possession of vision with the right eye. It laid hold of things as usual, and ran about the laboratory in every direction, passing obstacles right and left with perfect precision, and ducking its head to pass underneath bars as it ran along the top of the waterpipes of the laboratory. No defect of vision, amblyopic or hemiopic, could be detected."

In another animal, ${ }^{1}$ the left angular gyrus was cauterised up to the parietal-occipital fissure (the posterior part of the corpus callosum being also divided at the same time).

"The left eye was securely closed, and the animal allowed to recover from its narcotic stupor. In half an hour it began to move about spontaneously, although rather unsteadily. An hour and a half after the operation it walked about the laboratory, knocking its head against legs of chairs, and other obstacles in its path. When a piece of apple was held under its nose, it grabbed it and ate. It continued to walk about here and there, every now and then coming to a dead halt full tilt against the wall. Three hours after the operation, it again, in running about the laboratory, came full tilt with its snout against the wall, where it rested. While it was resting quietly, we crept up to it; but the animal, though with eye wide open, and looking towards us, made no sign of perception. Threatening grimaces were likewise without effect; but on making a noise with our lips, the animal seemed alarmed, peered forwards, and yet, though it came quite close to our faces, seemed to see nothing. It was tried to right and left in the same way, but there was no sign of vision, to one side or the other. Next day, the left eye being still closed, the animal ran about in every direction, ducking under bars, passing objects to right and left with the utmost precision, and never once knocking against anything one side or the other. Not the slightest impair-

1 Experin:snt 7, 'Phil. Trans.' part 2, 1881. 
ment of vision could be detected; and it was able to pick up the minutest objects lying about its cage, or thrown down near it."

Similar results were obtained in many other instances, and if in some they were even more transient, this may have been due to less extensive destruction, or perhaps to differences in animals as to the relative importance of this region in the ordinary exercise of their visual faculties.

But these facts, carefully noted and faithfully recorded by Professor Yeo and myself, are altogether unintelligible on the hypothesis that they are merely due to functional perturbation of a centre, the destruction of which causes only hemiopia. If, nevertheless, it should still be asserted that the results, being so transient, indicate rather functional perturbation than the cross relationship which I hold to exist between the eye and the angular gyrus, it would be natural to expect, that the much more severe operation of actual extirpation of a large portion of both occipital lobes would produce a greater disturbance of the visual centres than the mere erosion of the surface of the angular gyrus. How then shall the following facts be explained ? ${ }^{1}$

"The occipital lobes were exposed on both sides in a monkey, and the surface exposed destroyed by the cautery, which was also passed deeply into the interior of the lobes so as to cause as much disorganisation as possible. Care was taken not to injure the angular gyrus. The operation was completed at 3.30 P.M.

“4.10 P.M.-The animal after lying in a state of stupor until now, begins to move, but staggers a good deal. The eyes are open, and the pupils are dilated. It indioated consciousness by turning its head when called to.

" 5.45 P.M.-Gives emphatic evidence of sight; ran away when I approached it, carefully avoiding obstacles. Seeing its cage door open, it entered, and monnted on its perch, carefully avoiding the cat which had taken up its quarters there. Tried to escape my hand when I offered to lay hold of it, but picked up a raisin which I had left on the perch."

Here is a case of extensive destruction of both occipital lobes, and yet in little more than two hours after this serious

1 Experiment 22, 'Phil. Trans.,' vol. 165, Part 2. 
operation, the animal gave the most emphatic evidences of precise vision. Or take the facts of the following case ${ }^{1}$ :-

"The occipital lobes were exposed in a small, rather weakly monkey, and the lobes severed by a perpendicular section with hot wires about a quarter of an inch posterior to the parieto-occipital fissure, so as to aroid all interference with the angular gyrus. The operation was completed at 4.30 P.M., the animal having by the time the wound was dressed almost completely regained consciousness.

" 4.45 P.M.-Began to move about in rather a staggering manner, but exhibiting no muscular paralysis.

"4.55.-Can see quite well, as it avoids obstacles, and when removed, regains its place by the fire."

Here is a case in which, after thoval of at least two-thirds of both occipital lobes, the animal indicated its possession of vision within half an hour after the operation.

Or take a third case ${ }^{2}$ :-

"In this animal the occipital region was exposed on both sides, and both occipital lobes were severed with the galvanic cautery and scooped out bodily. The line of incision in both cases passed between the anterior extremity of the first occipital, and the parieto-occipital sulcus. The portion removed on the right side weighed 1.9 grammes; that removed on the left weighed $2 \cdot 1$ grammes [fully two-thirds of the whole].

"In half an hour after the operation the animal sat up and wanted to move about, but it was kept still, wrapped in a blanket to prevent the risk of hemorrhage. Both eyes were open equally, the pupils smallish, and the conjunctival reflex equally distinct on both sides. For two hours, though it was looking about as though it saw, no definite test of vision was made; but at the end of that time, it went and sat down beside the next cage, and allowed the other monkeys to handle it and examine its head. It then, of its own accord, went into its own cage and sat down. A piece of apple was thrown into the cage, and though it fell a full arm's length away, the animal, without the slightest hesitation or want of precision, put forth its left hand, picked it up and ate. Half an hour later, similar tests were made. A piece of apple was thrown near it; this it took and began to eat: on the piece being taken

' Experiment 23, 'Phil. Truns.,' vol. 165, part 2.

2 Experiuent 4, 'Phil. 'Traus.,' 1884. 
from it, it seized another piece lying in the cage and ate this, and having finished it, came forward a few steps and picked up another piece lying on the floor."

There was thus the most complete proof of retention of vision. Here again, within two hours after removal of at least two-thirds of the occipital lobes on both sides (see photograph plate 21, Fig. 15) the animal indicated sufficiently clear vision to be able to pick up a minute object lying on the floor. Within, therefore, the time at which animals with unilateral or bilateral destruction of the angular gyrus are blind on one or both sides, the much more formidable operation of destruction of the greater portion of both occipital lobes leaves the animal's power of vision practically unimpaired, so far as ordinary tests are concerned. It is surely therefore unreasonable to ascribe the effects of mere erosion of the angular gyrus to functional disturbance of the occipital lobe.

I do not, however, argue-as I at first believed-that the occipital lobes do not form part of the visual centres, but conclude from these facts, that greater relative disturbances of vision occur from lesions of the angular gyri than from much more extensive lesions of the occipital lobes. They show also, what an enormous amount of destruction can be inflicted on the sensory or perceptive centres of the cortex without obvious impairment of their functions.

I have always, in contending for the negative effects of extensive removal of the occipital lobes, specially made the proviso, that the lesions shall not extend up to the parieto. occipital fissure. For I was myself the first to point out that, when the lesions extended so far forwards, impairment of vision, or even total blindness, ensued-results which I attributed to direct implication of the angular gyrus, or its medullary connections.

That this is the real explanation of the total blindness obtained by Munk and Schäfer on removal of the occipital lobes, it will not, I think, be difficult to demonstrate, and that, too, even from Professor Schäfer's own facts alone.

If his Figure 3, p. 368, be examined, which represents the extent of the lesion in a monkey said to have been rendered 
totally and persistently blind, it will be seen that the lesion extended on the occipito-temporal aspect beyond the anterior limit of a line drawn along the course of the parieto-occipital fissure. On both sides, and particularly on the left, the lesion extends well into the collateral fissure and beyond the anterior boundary of the occipital lobe proper. (A similar condition, even more marked, exists in the brain of the hemiopic monkey, Fig. 2, as I have found on personal examination.) If the next figure-Fig. 4-be examined, in which vision was not abolished, it will be seen that the lesion, though it extends slightly beyond the limits of the occipital lobe proper, does not extend so far forwards as in the first case.

On this the whole question turns.

Professor Schäfer admits that, with the exception of this difference, the removal of the occipital lobes was equally complete in both cases. It is obvious, however, that if it were merely a question of removal of the occipital lobes, the results should have been precisely the same. The conclusion to be drawn from this is that the total blindness was due to implication of the region lying in front of the line of the parieto-occipital fissure. Other facts, some of which have also been supplied by Professor Schäfer himself, place this beyond all doubt.

I have recorded several instances ${ }^{1}$ in which in attempts to remove the hippocampal region, I have observed, in addition to other symptoms, hemiopia of greater or less degree and duration. In one of these ${ }^{2}$ there was only superficial erosion of the surface of the inferior occipital convolution; but at the anterior extremity of this gyrus, where it becomes continnous with the middle temporal convolution, and just at the lower extremity of the parieto-occipital fissure, the lesion became more deep, and thence extended along the middle temporal convolution, detaching all below this.

In another case $^{3}$ the occipital lobe was altogether uninjured, the lesion commencing just below the inferior extremity of the parieto-occipital fissure.

1 See Experiments 27, 28, Photographs, Fig. 125 and Fig. 134, 'Phil. Trans., part 2, 1884.

2 Experiment 27, Fige. 125-132.

- Expcriment 28, Fig. 134, 1. c. 
Professor Schäfer tells us that he too has observed hemiopia of temporary duration as the result of extensive lesions of the temporal lobe. ${ }^{1}$

It is evident that the hemiopia observed in these experiments does not indicate the position of the visual centres. For from these facts alone we should have as much reason for placing the visual centres in the temporal as in the occipital lobe.

There can be no doubt that the hemiopia in these cases was due to the lesion invading the occipito-temporal region, where the inferior occipital becomes continuous with the middle temporal convolution.

This point is situated on a level with, and opposite, the entrance into the hemisphere of the optic radiations from the corpora geniculata and primary optic ganglia.

It is to section of the optic radiations in this region that Professor Schäfer's results are to be ascribed. It is these which were destroyed completely in the case in which complete blindness occurred, and only partially injured in the case in which a large amount of vision was retained. Professor Schäfer cannot say, that the degree of vision retained by the latter animal depended on the cortex of the occipito-temporal region not being completely removed. For he relates a case in which, after complete recovery from any temporary effects caused by extensive removal of the occipital lobes, the destruction of the angular gyrus - without any lesion of the occipito-temporal region in question-caused complete and persistent hemiopia (p. 363).

Professor Schäfer has himself furnished me with so many facts showing that the visual centres are not confined to the occipital lobes proper, but embrace also the angular gyri, that it seems unnecessary for me to insist further on the subject.

Indeed, he appears himself to have some suspicion that " fibres connected with the cortex of the adjoining parts of the brain (and especially of the angular gyrus) may curve backwards into the occipital lobe, and thus become cut off along with that lobe" (p. 372).

1 "The nearer to the occipital lobe that any such lesion of the temporal lobe is carried, the greater probability is there of the occurrence of (temporary) hemiopia" (p. 372).

VOL. $\mathrm{XI}$. 
30 SCHÄFER ON THE TEMPORAL AND OCCIPITAL LOBES.

It is a pity that he did not examine his own facts a little more closely before committing himself as he has done. For he would have seen that the really effective lesions causing complete and permanent hemiopia-apart from conjoint destruction of the occipital lobe and angular gyrus-were those which severed the optic radiations in the position I have above indicated. And if Professor Schäfer will restrict his lesions to this region, without at all injuring the cortex of the angular gyrus or occipital lobe, he will obtain all the results which he attributes to removal of the occipital lobe itself.

While regretting for his own sake the attitude he has taken up on this quèstion, I cannot feel otherwise than indebted to him for inducing me by his criticisms to re-examine, and, as the result, to re-affirm, with increased conviction, the views which I have previously enunciated.

\section{POSTSCRIPT.}

The Editor of 'Brain' has received the following note from Prof. Schäfer, with reference to an objection raised by Prof. Ferrier to the term " Report" used by him in the January number of this Journal :-

"A statement in my Paper in the last number of 'Brain,' regarding a report by members of a Committee of the Neurological Society having been understood to imply that a Collective. Report had been published, I wish to state that the report here alluded to was an individual expression of opinion supplied to me by those members of the Committee (Drs. Bastian, Brunton and Waller) who took part in the investigation, and which it was agreed to substitute for a Collective Report." 